\title{
Management of postprandial hypoglycemia due to late dumping syndrome after direct percutaneous endoscopic jejunostomy (D-PEJ) with miglitol and an isomaltulose- containing enteral formula
}

\author{
Ezekiel Wong Toh Yoon* and Hisaaki Morishita \\ Department of Internal Medicine, Hiroshima Kyoritsu Hospital, Hiroshima City, Japan
}

\begin{abstract}
Postprandial hypoglycemia due to late dumping syndrome can occur in patients who have undergone upper gastrointestinal surgery or in patients receiving direct jejunal feeding. We experienced a case of postprandial hypoglycemia in a female patient who underwent direct percutaneous endoscopic jejunostomy (D-PEJ) for enteral nutrition. The patient was mostly asymptomatic and diagnosis was established using continuous glucose monitoring (CGM). Management with miglitol alone was not sufficient but by using an isomaltulose-containing enteral formula, her postprandial glucose metabolism improved tremendously, enabling the patient to be discharged uneventfully.
\end{abstract}

\section{Introduction}

One of the postoperative complications of gastric resection is postprandial hypoglycemia which is often referred to as late dumping syndrome $[1,2]$. The loss of gastric reservoir function due to the resection of the pylorus leads to rapid inflow of carbohydrates into the small intestine during feeding, which in turn causes high amount of insulin secretion. Reactive hypoglycemia occurs following a postprandial insulin peak when there is insufficient substrate influx to sustain blood glucose levels.

Post gastrectomy patients who are receiving enteral nutrition via direct jejunal feeding may be particularly at risk because they are often bedridden and do not complain. We herein report a case of postprandial hypoglycemia in a 70 -year-old bedridden woman who had been receiving jejunal feeding via a direct percutaneous endoscopic jejunostomy (D-PEJ) performed 9 years ago.

\section{Case report}

The patient was a 70-year-old woman in a nursing home. 9 years ago, she suffered from cerebral haemorrhage and was rendered bedridden with dysphagia. Long term enteral nutrition was required but due to a previous gastric resection, percutaneous endoscopic gastrostomy (PEG) could not be safely performed and the patient underwent D-PEJ for percutaneous tube feeding (Figure 1). Fluoroscopic imaging during the D-PEJ procedure is shown in figure 2. Tube placement with a 20Fr size bumper-tube type catheter (using the Push technique) was performed after identifying the puncture site and contrast medium was inserted after operation to confirm procedural success (Figure 2A,2B). The endoscopic image after tube placement is shown in Figure 3. Enteral feed was infused directly into the jejunum using gravitycontrolled infusion.

She was being treated for urinary tract infection in the nursing home but because of marked glycosuria, blood glucose was also frequently measured. During monitoring, hypoglycaemia was often observed and she was referred to our hospital for further evaluation. At presentation, her vital signs were normal and physical examination did not reveal any remarkable findings. However, her body mass index was $15.7 \mathrm{~kg} / \mathrm{m}^{2}$, indicating the presence of chronic malnourishment. Laboratory findings at presentation is summarized in table 1. Despite having glycosuria, her postprandial glucose was low at $54 \mathrm{mg} / \mathrm{dL}$.

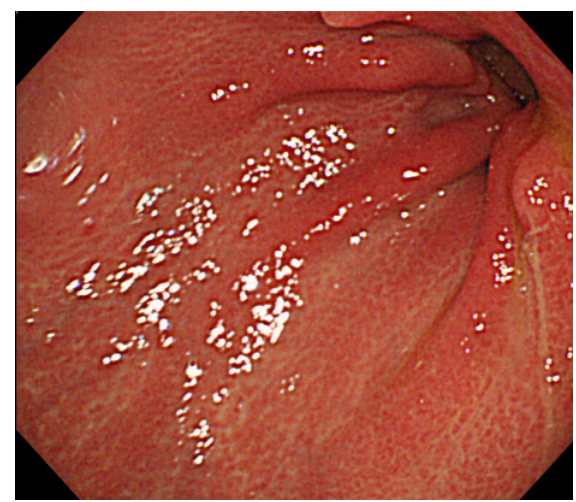

Figure 1. Endoscopic image confirming a previous gastric resection (Billroth I).

Correspondence to: Ezekiel Wong Toh Yoon, Department of Internal Medicine, Hiroshima Kyoritsu Hospital, 2-20-20 Nakasu Asaminami-ku Hiroshima City, Japan, Tel: 8182-879-1111; E-mail: easybs@hotmail.com

Key words: direct percutaneous endoscopic jejunostomy, postprandial hypoglycemia, late dumping syndrome, miglitol, isomaltulose

Received: September 19, 2016; Accepted: October 18, 2016; Published: November 07, 2016 
Toh Yoon EW (2016) Management of postprandial hypoglycemia due to late dumping syndrome after direct percutaneous endoscopic jejunostomy (D-PEJ) with miglitol and an isomaltulose-containing enteral formula

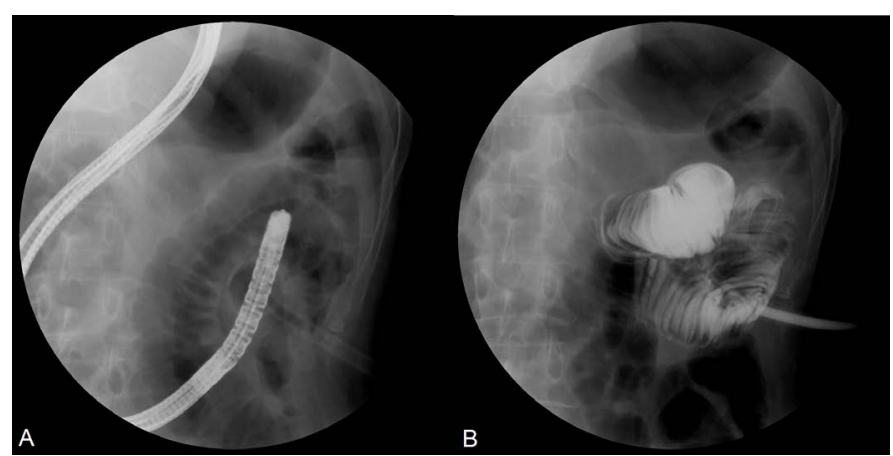

Figure 2. D-PEJ performed under fluoroscopy to achieve percutaneous enteral feeding.

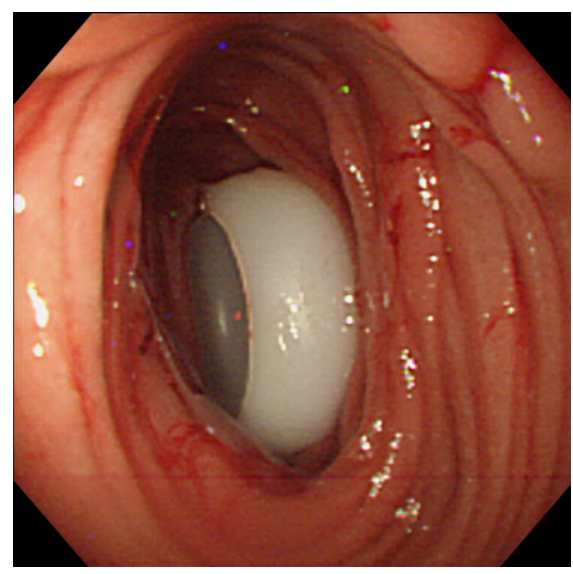

Figure 3. Endoscopic image after tube placement.

Table 1. Laboratory data on admission

\begin{tabular}{|l|l|l|l|}
\hline WBC & $7,840 / \mu \mathrm{L}$ & BUN & $11.1 \mathrm{mg} / \mathrm{dL}$ \\
\hline RBC & $407 \times 10^{4} / \mu \mathrm{L}$ & $\mathbf{C r}$ & $0.31 \mathrm{mg} / \mathrm{dL}$ \\
\hline Hb & $12.5 \mathrm{~g} / \mathrm{dL}$ & Na & $133 \mathrm{mEq} / \mathrm{L}$ \\
\hline Ht & $36.8 \%$ & K & $4.8 \mathrm{mEq} / \mathrm{L}$ \\
\hline PIt & $40.9 \times 10^{4} / \mu \mathrm{L}$ & Cl & $96 \mathrm{mEq} / \mathrm{L}$ \\
\hline CRP & $1.12 \mathrm{mg} / \mathrm{dL}$ & PPG & $54 \mathrm{mg} / \mathrm{dL}$ \\
\hline T-Bil & $0.2 \mathrm{mg} / \mathrm{dL}$ & HbA1c & $5.4 \%$ \\
\hline AST & $46 \mathrm{U} / \mathrm{L}$ & FT3 & $5.4 \mathrm{pg} / \mathrm{mL}$ \\
\hline ALT & $19 \mathrm{U} / \mathrm{L}$ & FT4 & $2.40 \mathrm{ng} / \mathrm{dL}$ \\
\hline LDH & $116 \mathrm{U} / \mathrm{L}$ & TSH & $3.23 \mu \mathrm{U} / \mathrm{mL}$ \\
\hline ALP & $456 \mathrm{U} / \mathrm{L}$ & ACTH & $21.2 \mathrm{pg} / \mathrm{mL}$ \\
\hline $\boldsymbol{\gamma}$-GTP & $203 \mathrm{U} / \mathrm{L}$ & Cortisol & $18.2 \mu \mathrm{g} / \mathrm{dL}$ \\
\hline AMY & $185 \mathrm{U} / \mathrm{L}$ & FSH & $46.6 \mathrm{mU} / \mathrm{mL}$ \\
\hline TC & $160 \mathrm{mg} / \mathrm{dL}$ & LH & $29.6 \mathrm{mU} / \mathrm{mL}$ \\
\hline LDL-C & $90 \mathrm{mg} / \mathrm{dL}$ & Prolactin & $17.9 \mathrm{ng} / \mathrm{mL}$ \\
\hline HDL-C & $56 \mathrm{mg} / \mathrm{dL}$ & IAA & $<0.4 \mathrm{U} / \mathrm{ml}$ \\
\hline TP & $6.8 \mathrm{~g} / \mathrm{dL}$ & & $(+)$ \\
\hline Alb & $3.2 \mathrm{~g} / \mathrm{dL}$ & Glucose & Urine analysis: \\
\hline
\end{tabular}

WBC: white blood cell count, RBC: red blood cell count, Hb: hemoglobin, Ht: hematocrit, Plt: platelet count, CRP: C-reactive protein, T-Bil: total bilirubin, AMY: amylase, TC: total cholesterol, TG: triglycerides, TP: total protein, Alb: albumin, BUN: blood urea nitrogen, Cr: creatinine, PPG: postprandial glucose, FT3: free triiodothyronine, FT4: free thyroxine, TSH; thyroid-stimulating hormone, ACTH: adrenocorticotropic hormone, FSH: folliclestimulating hormone, LH: luteinizing hormone, IAA: insulin autoantibodies.

Endocrine function was mostly within the normal limits. Although the patient was asymptomatic at presentation, we learned that she occasionally sweated profusely after meals. She was admitted into our hospital on the same day for further evaluation.

A CT scan to rule out the presence of insulinoma and pancreatic disease revealed no abnormalities. Continuous glucose monitoring (CGM) was performed to analyse the change in blood glucose level throughout the day. As shown by the CGM chart in Figure 4 (red arrows indicating feeding time), postprandial changes in blood glucose levels was characterized by marked hyperglycemia which was then followed by hypoglycaemia (mean value with SD: $109 \pm 98 \mathrm{mg} / \mathrm{dL}$, range: $40-389 \mathrm{mg} / \mathrm{dL}$ ).

The presence of postprandial hypoglycemia was confirmed and a diagnosis of late dumping syndrome was made. The patient was first treated with miglitol ( $50 \mathrm{mg} 3$ times daily at the start of each meal), a potent alpha-glucosidase inhibitor. As seen in Figure 5, slight improvement was observed after initiation of therapy but postprandial hypoglycemia was still prominent (mean value with SD: $107 \pm 54 \mathrm{mg}$ / $\mathrm{dL}$, range: $40-217 \mathrm{mg} / \mathrm{dL}$ ).

The dosage of miglitol was increased to $75 \mathrm{mg} 3$ times daily at the start of each meal. Furthermore, an isomaltulose-containing enteral formula (Inslow ${ }^{\oplus}$, Meiji Co., Ltd) was also used, replacing her regular enteral feed. Inslow ${ }^{\oplus}$ is a polymeric formula containing $1 \mathrm{kcal} / \mathrm{mL}(50 \%$ Carbohydrates, 30\% Lipids and 20\% Protein), with more than half of the carbohydrates provided in the form of isomaltulose (palatinose), a slow digestible disaccharide. Figure 6 shows the CGM chart for the patient after commencing this treatment regimen, with marked improvement in her blood glucose levels observed (mean value with SD: $89 \pm 17 \mathrm{mg} / \mathrm{dL}$, range: $63-143 \mathrm{mg} / \mathrm{dL}$ ). The treatment regimen was well tolerated and she was discharged without further complications.

\section{Discussion}

As long as gut integrity is intact, enteral nutrition is always preferable. For patients with impaired oral intake that require long term enteral nutrition, a percutaneous tube feeding route with PEG is indicated in most cases $[3,4]$. However, in patients with a previous gastric resection, PEG may not always be a viable option and could lead to serious complications [5]. For such cases, direct jejunal feeding is an alternative. Although jejunal feeding may be achieved using percutaneous endoscopic transgastric jejunostomy (PEG-J), this method requires passage via the gastric lumen $[6,7]$. Laparotomy and laparoscopy approaches are also available but the least invasive method for direct access to the jejunum is via D-PEJ [8].

Postprandial hypoglycemia may occur in 5 to 37 percent of patients who have undergone upper gastrointestinal surgery $[1,2]$. When the cause of postprandial hypoglycemia is alimentary and the occurrence hours after a meal, the term late dumping syndrome is used, which should be distinguished from early dumping syndrome, occurring 15 to 30 minutes after a meal and is associated with changing osmotic gradient as well as the release of vasoactive hormones [9]. Other causes of postprandial hypoglycemia such as factitious hypoglycemia from insulin or sulfonylurea, insulin autoimmune hypoglycemia and insulinoma should also be taken into account during differential diagnosis.

Postprandial hypoglycemia due to late dumping syndrome in patients with direct jejunal feeding may be under-reported because patients are often bedridden and do not complain. Although this condition have been reported in post-pyloric feeding due to the migration of the PEG tube, there is limited literature on the frequency of late dumping syndrome in patients receiving jejunal feeding [10]. When postprandial hypoglycemia is suspected in these patients, the best way to confirm this would be through the use of CGM [11]. Although the classical Whipple's triad is useful to establish the diagnosis of 
Toh Yoon EW (2016) Management of postprandial hypoglycemia due to late dumping syndrome after direct percutaneous endoscopic jejunostomy (D-PEJ) with miglitol and an isomaltulose-containing enteral formula

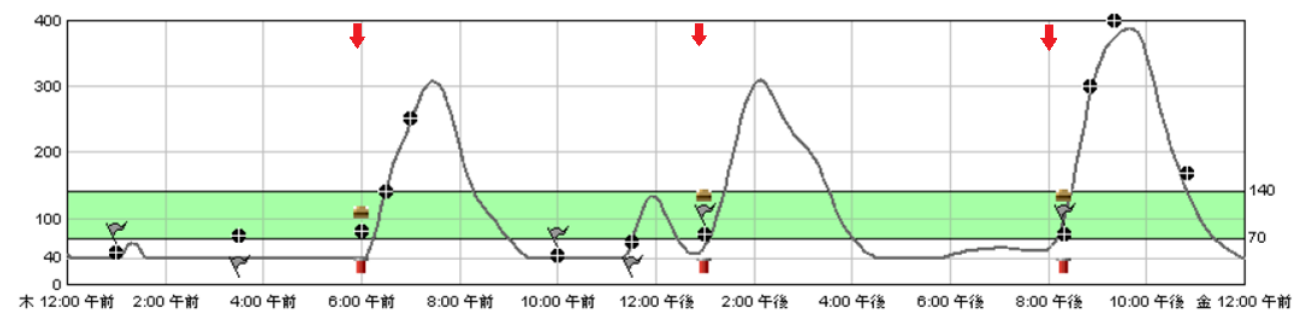

Figure 4. Continuous glucose monitoring (CGM) chart before treatment (the red arrows indicating feeding time).

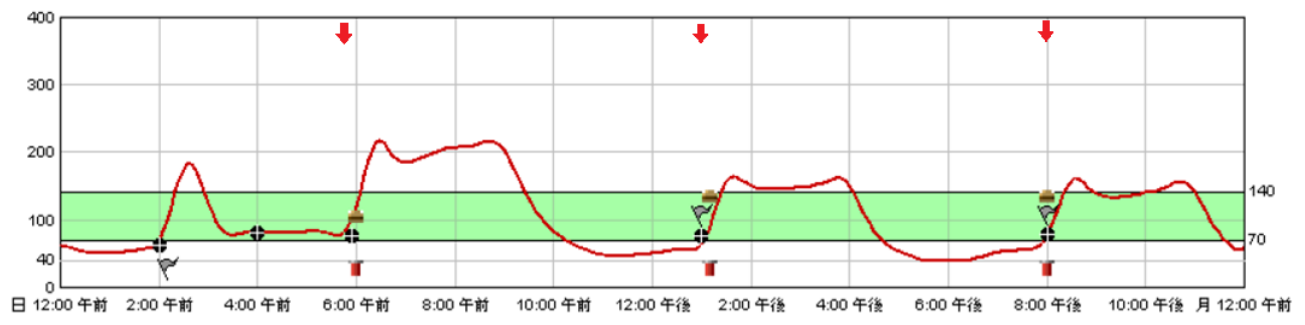

Figure 5. CGM chart after initiating treatment with $50 \mathrm{mg}$ miglitol.

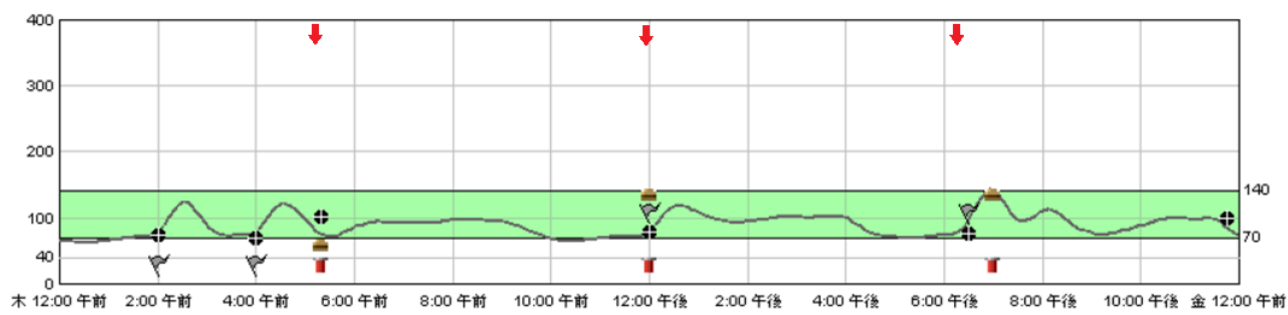

Figure 6. CGM chart after initiating treatment with $75 \mathrm{mg}$ miglitol and enteral feeding with Inslow ${ }^{\circledR}$.

hypoglycemia in adult patients, this may be difficult to confirm in bedridden patients who do not complain. As in our patient, CGM was useful in the diagnosis of postprandial hypoglycemia but when CGM is not available, repetitive glucose measurement after infusion of enteral feed maybe an alternative.

Once diagnosis is established, the condition can be managed using a low-carbohydrate diet followed by the addition of alpha-glucosidase inhibitors such as miglitol if no improvement is seen [12]. In our patient's case, therapy was initiated with miglitol because she was on enteral nutrition. However, when miglitol was not effective enough to prevent postprandial hypoglycemia, an isomaltulose-containing enteral formula was employed instead of her regular enteral formula. Isomaltulose (palatinose) is a slow digestible disaccharide with a low glycemic index that has been shown to inhibit glucose absorption, lower postprandial insulin levels and improve postprandial glucose metabolism [13-15]. In our patient, marked improvement was observed after its use.

In conclusion, we reported the successful management of postprandial hypoglycemia due to late dumping syndrome in a patient with direct jejunal feeding, using miglitol and an isomaltulosecontaining enteral formula. Although this condition may be underreported in patients with similar backgrounds, once a diagnosis is established, management through the use of alpha-glucosidase inhibitors and enteral formulas with low glycemic indexes is possible.

\section{References}

1. Gilbert JA, Dunlop DM (1947) Hypoglycaemia following partial gastrectomy. Br Med $J$ 2: 330-332. [Crossref]

2. Leichter SB, Permutt MA (1975) Effect of adrenergic agents on postgastrectomy hypoglycemia. Diabetes 24: 1005-1010. [Crossref]

3. Gauderer MW, Ponsky JL, Izant RJ Jr (1980) Gastrostomy without laparotomy: a percutaneous endoscopic technique. J Pediatr Surg 15: 872-875. [Crossref]

4. DeLegge MH (2007) Percutaneous endoscopic gastrostomy. Am J Gastroenterol 102 2620-2623. [Crossref]

5. Toh Yoon EW, Nishihara K (2016) Liver mispuncture during percutaneous endoscopic gastrostomy in a patient with a partial gastrectomy. Endoscopy 48 Suppl 1: E182. [Crossref]

6. Toh Yoon EW, Yoneda K, Nakamura S, Nishihara K (2016) Percutaneous endoscopic transgastric jejunostomy (PEG-J): a retrospective analysis on its utility in maintaining enteral nutrition after unsuccessful gastric feeding. BMJ Open Gastroenterol 3:e000098. [Crossref]

7. Toh Yoon EW (2016) The Role of Percutaneous Endoscopic Transgastric Jejunostomy in the Management of Enteral Tube Feeding. Gastroenterol Res 9: 53-55.

8. Shike M, Schroy P, Ritchie MA, Lightdale CJ, Morse R (1987) Percutaneous endoscopic jejunostomy in cancer patients with previous gastric resection. Gastrointest Endosc 33: 372-374

9. Eagon JC, Miedema BW, Kelly KA (1992) Postgastrectomy syndromes. Surg Clin North Am 72: 445-465. [Crossref]

10. Shimoda M, Saraya T, Ogawa Y, Tanaka Y (2015) Dumping Syndrome due to the Misplacement of the Gastrostomy Feeding Tube. Intern Med 54: 2529. [Crossref]

11. Kishimoto M, Noda M (2015) Verification of glycemic profiles using continuous glucose monitoring: cases with steroid use, liver cirrhosis, enteral nutrition, or late 
Toh Yoon EW (2016) Management of postprandial hypoglycemia due to late dumping syndrome after direct percutaneous endoscopic jejunostomy (D-PEJ) with miglitol and an isomaltulose-containing enteral formula

dumping syndrome. J Med Invest 62: 1-10. [Crossref]

12. Hirose S, Iwahashi Y, Seo A, Sumiyoshi M, Takahashi T, et al. (2016) Concurrent Therapy with a Low-carbohydrate Diet and Miglitol Remarkably Improved the Postprandial Blood Glucose and Insulin Levels in a Patient with Reactive Hypoglycemia due to Late Dumping Syndrome. Intern Med 55: 1137-1142. [Crossref]

13. Kashimura J, Nagai Y (2007) Inhibitory effect of palatinose on glucose absorption in everted rat gut. J Nutr Sci Vitaminol (Tokyo) 53: 87-89. [Crossref]

14. Holub I, Gostner A, Theis S, Nosek L, Kudlich T, et al. (2010) Novel findings on the metabolic effects of the low glycaemic carbohydrate isomaltulose (Palatinose). $\mathrm{Br} \mathrm{J}$ Nutr 103: 1730-1737. [Crossref]

15. Ang M, Linn T (2014) Comparison of the effects of slowly and rapidly absorbed carbohydrates on postprandial glucose metabolism in type 2 diabetes mellitus patients: a randomized trial. Am J Clin Nutr 100: 1059-1068. [Crossref]

Copyright: $\ 2016$ Toh Yoon EW. This is an open-access article distributed under the terms of the Creative Commons Attribution License, which permits unrestricted use, distribution, and reproduction in any medium, provided the original author and source are credited. 